\title{
Emergencias de la mediación intelectual. $L a$ Revista de América (París, 1912-1914) y la red de escritores latinoamericanos en Europa a comienzos del siglo $\mathrm{XX}$
}

\author{
Margarita MERBILHAÁ \\ CONICET/IdHICS UNLP, Argentina \\ margaritamerbilhaa@yahoo.com
}

\begin{abstract}
RESUMEN
Este trabajo estudia el proyecto editorial de la Revista de América (1912-1914), fundada en París y dirigida por Francisco García Calderón. Mi propósito es analizar el modo en que muchos de los vínculos entre los escritores latinoamericanos radicados en París entre fines del siglo XIX y la Primera Guerra Mundial se materializaron en la edición de revistas. Propongo examinar las estrategias de difusión de las producciones latinoamericanas en el Viejo Continente, como así también algunos aspectos ideológicos y de intervención intelectual que la revista llegó a articular. En un primer momento, me detengo en los rasgos materiales tanto del proyecto editorial de la revista como de los vínculos entre los latinoamericanos desterrados. Luego indago las distintas formas de mediación crítica, por un lado, y cultural, por otro, que la revista escenificó y, en algunos casos, desarrolló activamente. En efecto, la revista de García Calderón vuelve visible una dimensión mediadora en varios sentidos: mediación crítica entre productores y lectores, pues se propuso como instancia de difusión, al convocar a "a los mejores escritores latinoamericanos". Al mismo tiempo, propuso otras dos mediaciones: entre pares, al funcionar como consagradora, seleccionando y agrupando simbólicamente a los escritores de cada país latinoamericano. Finalmente, una mediación intercontinental entre culturas en la contemporaneidad, que intentó acercar dos gestos en la acción de la revista: una legitimación del pensamiento y el arte "de ultramar" y una valoración de los desarrollos artísticos europeos del presente.
\end{abstract}

Palabras claves Revista de América, latinoamericanismo, Modernismo, mediaciones entre América Latina y Europa.

Emergencies of the intellectual mediation. La Revista de América (Paris, 1912-1914) and the network of Latin-American writers in Europe at the beginning of the 20th century

\footnotetext{
ABSTRACT

My purpose consists in studying the Revista de América, founded and directed in Paris by Francisco García Calderón, as a publishing project. I focus on the links between latin
} 
American writers living there from the end of XIXth Century to the First World War, most of which were materialized in Publishing reviews. I intend to examine the diffusion of latin American productions in Europe, as well as some ideologic aspects and of intellectual intervention, that were articulated by this review. I firstly study its material caracteristics, both of the review's publishing politics and of the links between exiled Latin-Americans. Then I try to analyze different ways of critical and cultural mediation, respectively, that have been carried out by the review: on the one hand, a critical mediation between writers and readers, by broadcasting the "bests of them". On the other hand, it has displayed a mediation in two senses: between pairs, being a selective way of consecration and kniting together writers from different countries in Latin America. Finally, through an intercontinental mediation among Europpean and Latin-American cultures that brought them closer by means of a double action of legitimating the "overseas" thinking and arts, and interpreting the European recent artistics and intellectual expressions.

Key words: Revista de América, latinoamericanism, Modernism, mediations between Latin America and Europe.

Este trabajo estudia el proyecto editorial de la Revista de América (1912-1914), fundada en París y dirigida por Francisco García Calderón. Mi propósito es analizar el modo en que muchos de los vínculos entre los escritores latinoamericanos radicados en París entre fines del siglo XIX y la Primera Guerra Mundial se materializaron en la edición de revistas. A partir de esto, intentaré examinar las estrategias de difusión de las producciones latinoamericanas en el Viejo Continente, como también algunos aspectos ideológicos y de intervención intelectual que la revista llegó a articular. En un primer momento, intentaré reconstruir los rasgos materiales tanto del proyecto editorial de la revista como de los vínculos entre los latinoamericanos desterrados. Luego indagaré las distintas formas de mediación crítica, por un lado, y cultural, por otro, que la revista escenificó y, en algunos casos, desarrolló activamente. En efecto, la revista de García Calderón vuelve visible una dimensión mediadora en varios sentidos: mediación crítica entre productores y lectores, pues se propuso como instancia de difusión, al convocar "a los mejores escritores latinoamericanos". Al mismo tiempo, propuso otras dos mediaciones: entre pares, al funcionar como consagradora, seleccionando y agrupando simbólicamente a los escritores de cada país latinoamericano. Finalmente, una mediación intercontinental entre culturas en la contemporaneidad, que intentó acercar dos gestos en la acción de la revista: una legitimación del pensamiento y el arte "de ultramar" y una valoración de los desarrollos artísticos europeos del presente.

El primer número de la revista sale a mediados de 1912, el mismo año en que su director publica Les démocraties latines de l'Amérique en la prestigiosa colección 
que dirigía Gustave Le Bon en la editorial Flammarion. ${ }^{1}$ Por entonces, el escritor peruano llevaba seis años viviendo en la capital francesa junto a sus hermanos, y se encontraba en un momento de intensa actividad intelectual: entre 1907 y 1912, había asistido a los cursos de filosofía en la Sorbona del filósofo espiritualista Émile Boutroux y de Bergson, entre otros, acercándose a los círculos universitarios de filosofía; había expuesto en el Congreso europeo de Filosofía y participado en otro en Heidelberg; llevaba publicados sus principales libros, con prólogos de filósofos franceses, y artículos en revistas francesas de filosofía, y había recibido un premio de la "Académie Française" por su Le Pérou contemporain (1907). También tenía libros editados en España y otros en proyecto ${ }^{2}$, y enviaba crónicas al Figaro de La Habana y La Nación de Buenos Aires, entre otros diarios de América. Ocupaba además un cargo en la legación peruana de París y más adelante accedería a un cargo en el consulado. ${ }^{3}$

Como se desprende de las cartas que envía a su amigo y compatriota José de la Riva Agüero y a Manuel Ugarte (a quien frecuentaba en París), el proyecto de fundar una revista dedicada a temas latinoamericanos había madurado desde al menos 1910. ${ }^{4} \mathrm{Su}$ propósito era asociar las mejores firmas del continente, para convertir a la revista en un medio de reunión y difusión de las producciones intelectuales de latinoamericanos. Pero significaba también, para García Calderón, una posibilidad de completar sus ingresos dedicándose a una actividad intelectual. En efecto, él no se pensaba meramente de paso por París, sino bien resuelto a permanecer allí y a vivir de su profesión de escritor. Así lo confiesa a Riva Agüero en algunas cartas, cuando su principal fuente de ingresos era el cargo diplomático, que sólo completaba con los tres libros que hasta el momento llevaba publicados (uno España por Maucci y dos en Francia por Ollendorf y Dujarric) y con las crónicas en la prensa latinoamericana. Es más, en una de esas cartas, la referencia

${ }^{1}$ El contacto de García Calderón con Gustave Le Bon, que acepta publicarle su libro en la Bibliothèque de philosophie scientifique, probablemente haya sido a través de quien prologara el libro de 1912, el físico Henri Poincaré, miembro de la Academia de Ciencias Francesa y amigo de Le Bon. Poincaré era cuñado del filósofo Émile Boutroux con quien García Calderón trabó una amistad.

2 Alcides Arguedas menciona en la dedicatoria de su libro La fundación de la República que en 1912 estaba en proyecto una Histoire des Nations de l'Amérique Latine bajo la dirección del historiador francés Seignobos, y que la parte sobre Perú del volumen 11 había sido encargada a Francisco García Calderón, mientras que la otra, sobre Bolivia, a él. La obra nunca salió a la luz a causa de la guerra mundial.

${ }^{3}$ Ver, al respecto, la completa cronología de Ángel Rama y Marlene Polo en la edición de Ayacucho de Las democracias latinas de América y La creación de un continente (1979).

4 Así figura en dos cartas de García Calderón de comienzos de 1910, conservadas en el epistolario de Ugarte (Buenos Aires, Archivo General de la Nación) y en otras a Riva Agüero de 1911 (Cf. Gonzales 2008 ). 
vaga a "ciertos negocios" posiblemente esté vinculada con el proyecto de edición de la revista, al que considera como una oportunidad para solventar su actividad intelectual:

Me pica la ambición de hacer algo aquí, formarse un nombre, si puedo, en Francia: me parece digno empeño para una alta ambición, pero todavía no sé. Ello depende del éxito de ciertos negocios en que estoy metido y que me darían, si me salen bien, completa independencia económica (París, 22 de setiembre de 1910). La idea de ser escritor aquí, te confieso que estimula mi imaginación de continuo. Me parece digna ambición, alto empeño en que el mismo fracaso sería menos triste. En fin, ya veremos (París, 26 de octubre de 1910). ${ }^{5}$

Ya en 1911 García Calderón comienza a pedir artículos a varios colaboradores. A excepción de las firmas de renombre, la mayoría de ellos tiene residencia europea, lo que refuerza, como veremos, la hipotesis de que existía un grupo humano detrás de la publicación, al que si bien la revista no contribuyó a estructurar, sí le imprimió una identidad intelectual y, a su vez, la alimentó.

Así, podemos entonces distinguir entre dos tipos de colaboradores: en primer lugar, los poetas y ensayistas más consagrados de América como Darío, a quien, además, García Calderón tiene a mano, y que aparecerá en el primer número; Ingenieros, ${ }^{6}$ en el número 2 y 3 y Rodó, en el número 3 (siendo anunciado su

${ }^{5}$ Ambas cartas aparecen citadas por Gonzales (2008). El autor también menciona la preocupación de García Calderón por encontrar una independencia económica que le permitiera liberarse de los compromisos intelectuales a que lo obligaba su cargo diplomático.

${ }^{6}$ El pensador argentino firma "Los forjadores de ideales" con la versión italiana de su apellido (Ingegnieros), que aparece en los números 2 y 3 (julio y agosto de 1912). Se trata del artículo que incluirá luego como último capítulo de El hombre mediocre (publicado en enero de 1913) en la editorial madrileña Renacimiento. En julio de 1913, el mismo año de publicación de El hombre mediocre, elige a esta revista para difundir su carta a Ricardo Rojas sobre "Nacionalismo e indianismo" ( $\left.n^{\circ} 14\right)$ que fue, según Fernando Degiovanni (2010), el único escrito que discutió explícitamente a Rojas su "nacionalismo retrospectivo", propio de las "viejas oligarquías feudales", y disputó esa concepción de la argentinidad como exclusiva de los descendientes hispano indígenas. En efecto, en esta carta a Rojas, anunciaba la pronta extinción del "indianismo feudal", a manos de la europeización que producirían los sectores inmigrantes, más aptos, según él, para continuar la tradición argentina que había nacido, a su juicio, con los hombres de la revolución de Mayo (y no de elementos previos, indígenas o coloniales). La elección de la revista de García Calderón no es fortuita: Ingenieros obsequia su artículo a la generación de jóvenes intelectuales, en un gesto que legitima su autoridad de profeta. Además, el latinismo de la revista está en armonía con las apelaciones a la raza latina en la que deposita las esperanzas de perpetuación de la tradición argentina (contra la confianza en los europeos del norte, por 
artículo en el número anterior). El segundo tipo de los colaboradores reclutados son, en la mayoría de los casos, escritores residentes en esa ciudad, en España, Bélgica o Gran Bretaña, o bien que estuvieron de paso por París y, por ende, a quienes el ensayista conoció directamente (por ejemplo, el argentino Manuel Gálvez que lo recuerda en su primer tomo de memorias). Aquí también podemos incluir el caso particular de un colaborar francés, Jean de Gourmont, a cargo de la sección "Letras francesas" de la revista, que era cercano a los latinoamericanos parisinos por los vínculos que su hermano Rémy, uno de los editores del Mercure de France, ${ }^{7}$ mantenía con ellos. Entre los demás colaboradores figuran los contemporáneos del escritor peruano, a quienes frecuenta con mayor o menor regularidad y que conforman su entorno o "milieu" (Prochasson 1993): Rufino Blanco Fombona, Alcides Arguedas, Juan Pablo Echagüe, Francisco Contreras, Manuel Ugarte, Amado Nervo, Enrique Gómez Carrillo, el escritor viajero Ángel de Estrada (hijo), Oliveira Lima (el historiador y miembro de la "Academia Brasilera", que en esos años era diplomático en Bélgica). ${ }^{8}$ De allí que el contacto cercano que se da en París, en algunos casos muy asiduo, permita explicar la incorporación de los artículos presentes en los primeros números de la revista, y de la mayoría de los siguientes. Basta cruzar los índices de la revista con algunas memorias y

parte de Alberdi, como ha observado certeramente Degiovanni). La revista le permite, por último, entablar diálogos con dos tipos de interlocutores a la vez: los jóvenes, en quienes deposita sus esperanzas, en el mismo sentido en que lo hacía en ese mismo momento, con los destinatarios de El hombre mediocre, tal como ha advertido Alejandra Mailhe (2013). En segundo lugar, la publicación del artículo lo acerca a los lectores latinoamericanos, a los que la revista se dirige. Ocurrida bien antes de su giro latinoamericanista, quizá sea ésta una de las primeras veces que Ingenieros destina sus escritos a un público latinoamericano, pues hasta entonces publicaba en las páginas del diario argentino La Nación o en publicaciones especializadas europeas.

${ }^{7}$ Jean de Gourmont era hermano de Rémy, uno de los directores de la emblemática revista decadentista que tanto leyeron los modernistas latinoamericanos. Rémy abrió una sección sobre letras hispano-americanas en dicha revista, la que estuvo a cargo de Pedro E. Coll y luego, Francisco Contreras. A través de él probablemente se haya dado el contacto de García Calderón con los hermanos Gourmont. Jean fue autor de varios libros sobre poetas contemporáneos y se ocupó de difundir la memoria de su hermano. Liliana Samurovic'Pavlovic' (1969: 106) recoge en su libro el testimonio directo del diplomático ZénegaFombona que frecuentó a Rémy de Gourmont y publicó en la editorial del Mercure de France. Según este diplomático venezolano, el interés del escritor francés por incluir la sección hispanoamericana en el Mercure surgió por la gran cantidad de suscripciones que Enrique Gómez Carrillo le había conseguido para su revista. Sobre el Mercure, ver también Lachasse (Pluet-Despatin et al. 2002).

${ }^{8}$ Oliveira Lima estaba ya en contacto con los escritorios latinoamericanos en París si se tiene en cuenta que, por ejemplo, fue colaborador de El Nuevo Mercurio de Gómez Carrillo, con un artículo sobre "Nuestras artes y letras juzgadas en el extranjero" (nº, 1907). 
correspondencias de los protagonistas para comprobar la coincidencia entre los nombres de los colaboradores y los amigos o relaciones. Entre ellos, podemos mencionar a Alcides Arguedas, que llega a París hacia 1908, y ubica en esa ciudad y época no el nacimiento de su vocación pero sí el inicio de una dedicación intensa a la escritura, y el de la publicación de sus obras como Pueblo enfermo que editará Ollendorf, y luego Vida criolla:

Toda esa primavera de París y el verano de Normandía del año 1908 los empleé en redactar Pueblo enfermo. Mi gabinete de trabajo en París era espléndido: el jardín de Luxemburgo.

[...] Ese fue el tiempo de las bellas relaciones y de los recuerdos imborrables.

[...] Se ensanchó el círculo de mis conocimientos literarios y tuve muchos y buenos amigos. Formamos nuestra peña intelectual con Manuel Ugarte, Blanco Fombona, Francisco García Calderón, Juan Pablo Echagüe, Hugo Barbagelata, Ciges Aparicio, Marín Ramos y tantos otros. Organizamos también un yantar quincenal. De vez en cuando se torna banquete el yantar y entre los discursos interesados en que se levantan y consolidan las plataformas se acentúa a la vez eso que Goethe llamó "afinidades electivas".

Pero no es sólo en torno a la mesa de los restaurantes que se afirman las relaciones. Las salas de redacción se abren también. Primero es Mundial; luego, La Revista de América e Hispania, de Londres, sin contar los muchos periódicos diarios del Continente que solicitan nuestra colaboración. Allí, en las revistas y diarios cobramos nuestros artículos, muchos de los cuales se reproducen en los mejores periódicos de América. ${ }^{9}$

Arguedas recuerda incluso las circunstancias en las que conoce a Francisco Contreras, que también participaba de esos encuentros y fue, de 1911 a 1915, redactor de las "Lettres hispano-américaines" en el Mercure de France. El vínculo vino a través de Ricardo Mayol, corresponsal de El Globo de Madrid, un periodista español que trabajaba en otra mesa del café del jardín de Luxemburgo. A través de Mayol, que era amigo de Luis Bonafoux, Arguedas comenzó también a frecuentar a este cronista español radicado en París, y corresponsal de El Heraldo de Madrid. También se acercó a Darío por sentir, como todos sus contemporáneos, "una secreta simpatía" hacia él. Son tiempos en los que impera la práctica de la visita al escritor consagrado, uno de los modos más frecuentes de "hacerse un nombre". ${ }^{10}$

\footnotetext{
${ }^{9}$ Arguedas 1959: 637; 640 y 644 respectivamente.
}

10 Propia de las épocas de baja profesionalización del oficio, esta modalidad parecía anclarse en la creencia en que el hecho de conocer el mundo privado de los escritores consagrados y mayores - a veces por no más de una década-, podía ofrecer elementos claves para orientar o forjar la propia carrera. La autoridad ejercida por Rodó entre los jóvenes en busca de un oficio compatible con las letras es otra característica común al grupo que nos ocupa. Así por ejemplo, durante un paso por el Río de La Plata antes de su regreso a 
Más allá de los objetivos personales, es posible revelar en todos ellos cierta estructura de sentimiento (Williams 1977) en torno a la necesidad de alejarse del país natal por vivir su ambiente como poco propicio a la vida intelectual, a la que percibían como opuesta a la vida material o al plutonismo y los efectos no deseados del progreso. Se trataba de una respuesta, claro está, a los fenomenales cambios producto de la modernización que siguió al ingreso de varios países sudamericanos al mercado mundial. Mientras Ugarte se refiere en sus memorias (1947) al sentimiento de "asfixia que sentía" en Buenos Aires y le impedía dedicarse a vivir de su pluma, Arguedas justificaba, en términos mucho más concretos, ante sus "amigos políticos y personajes representativos" (1959: 677) su intención de alejarse del ambiente local:

Yo he resuelto irme del país en busca de un ambiente favorable a mis afanes de escritor. Como mis recursos propios son muy limitados, no podré trabajar ya en nuestra historia [...] pues tengo que emplear mi tiempo en otro género de labores de alguna utilidad para mí: escribir para periódicos de América, colaborar en los de España, traducir libros del francés por cuenta de casas editoras, hacer algo, en fin, que aumente mis medios de vida mediante cualquier trabajo honrado: ahora bien, el gobierno me ha hecho ofrecer un cargo representativo en Francia, que no tiene nada que ver con nuestra política interna... (1959:677)

En este recuerdo, Arguedas, hijo de una familia acomodada que había solventado, por ejemplo, su primer viaje al viejo continente entre 1903 y 1905 , resume todo el abanico de labores que hacían a la actividad intelectual de los latinoamericanos en Europa, y las condiciones en que escribían. Sólo faltó a esta lista la fundación y dirección de revistas, una de las prácticas más frecuentes entre los latinoamericanos, empezando por su escritor faro, Darío, que a lo largo de su vida dirigió publicaciones como un medio de subsistencia, y no exclusivamente con

Francia, Arguedas viaja a Montevideo para visitar al "maestro indiscutido de toda la juventud estudiosa de América" (Arguedas 1959: 649). Rodó lo recibe, comenta su Pueblo enfermo, le regala una edición de Motivos de Proteo y lo honra revelándole los motivos por los que ha dejado de escribir para La Nación. Le da sus consejos mientras comenta su propia experiencia:

El periódico es bueno para facilitar la producción de los comienzos, pero después hay que dejarlo, porque no permite hacer una labor durable. Yo aconsejo a los jóvenes el periodismo como una gimnasia muy útil, a condición de que no se consagren a él por entero...

Hablando, hablando, llegamos a sus métodos de trabajo. Y me cuenta con acento confidencial:

- Yo trabajo regularmente todos los días. Escribo una página o dos y las guardo y no las reviso en mucho tiempo. Sólo al cabo de meses y aun de años me pongo a releerlas. Y si me gustan, entonces las guardo para hacer un libro [...]. Le aconsejo hacer lo mismo... (Arguedas 651). 
propósitos artísticos o intelectuales, tal como se desprende de su Autobiografía. ${ }^{11}$ Prueba de esta práctica frecuente entre los modernistas, es la contemporaneidad de otros proyectos de edición de revistas como La Revue Sud-Américaine de Lugones; Mundial Magazine, la empresa cultural de los hermanos Guido, dos banqueros uruguayos que contratan a Darío para dirigirla; Ariel. Revista de arte libre (19121913), de Alejandro Sux, o también Gustos y gestos (París, 1910-1911) cuyo director era el dibujante Leo Merelo. Están incluso aquellos planes no concretados que nos dan una dimensión de la centralidad de los proyectos de publicaciones que respondían a objetivos político intelectuales pero que se pensaban sobre todo como una posibilidad de obtener de ingresos surgidos de la profesión intelectual. Pueden citarse por ejemplo, el proyecto de Ugarte de crear una revista junto a Barbagelata en 1910, ${ }^{12}$ o el proyecto editorial que menciona el escritor español Manuel Ciges Aparicio $^{13}$ (uno de los partícipes de la " peña intelectual " recordada por Arguedas). En este marco de intenciones o disposiciones se inscribe también la exitosa Editorial-América que Blanco-Fombona fundaría en Madrid, en 1915. ${ }^{14}$

A estas condiciones, digamos, subjetivas se suman las posibilidades que ofrecía la capital francesa para los emprendimientos revisteriles, desde los costos más accesibles de publicación, con respecto a los de Buenos Aires o Lima, hasta los modelos disponibles de revistas juveniles de esa ciudad. No olvidemos, en este sentido, que el período 1880-1914 conoció en Francia una expansión y proliferación de las revistas culturales tanto vanguardistas (Le Mercure de France o La Plume) como de gran circulación y asociadas a editoriales importantes (Piénsese en la Revue des Deux Mondes, La Revue Blanche y la Revue de Paris). En cuanto a las ventas, cuestión que retomaré más adelante, las posibilidades de conseguir lectores/consumidores también se ampliaban pues la difusión desde la capital francesa era más fluida que desde cualquier capital latinoamericana, un circuito allanado por las editoriales francesas de libros en español como Garnier, Ollendorf, Louis-Michaud o Bouret. De este modo, la llegada -y repercusión- de las revistas podía ser mayor desde París. Pero además, las revistas apuntaban a los residentes

${ }^{11}$ Darío integró la redacción de varios periódicos de Chile y Centroamérica y dirigió dos periódicos, uno en Nicaragua y otro en Guatemala, en 1889 y 1890, además de La Revista de América (1894) y Mundial (1911-1914). Darío reflexionó además sobre las nuevas condiciones de producción y difusión que presentaban las publicaciones periódicas en "La cuestión de la revista. La caricatura" (La nación, 20/07/1899).

12 Carta de Hugo Barbagelata a Ugarte del 13/02/1910 (Archivo Manuel Ugarte, Tomo I, Archivo General de la Nación). Este historiador y crítico uruguayo dirigirá en la década de 1920 la editorial Biblioteca Latino-Americana, que estuvo asociada en Buenos Aires con la Agencia General de Librería y Publicaciones.

${ }^{13}$ Se trata probablemente de actividades vinculadas a su desempeño como director de la sección española de la Casa editorial Michaud (editorial muy publicitada en la revista).

${ }^{14}$ Cf. Segnini (2000). 
latinoamericanos en Europa, es decir, no sólo a hombres de letras sino a empresarios, diplomáticos o viajeros. A ellos destinaban las publicidades de moda masculina y femenina o de viajes transatlánticos que aparecen en sus páginas, modalidad que llegó a adoptar aun una revista "seria" como la de los García Calderón, que optarán, como veremos, por agregar un suplemento especial ilustrado, de tipo misceláneo, para traer a un lectorado menos "intelectual ". 15 Entonces, si bien me centro aquí en la Revista de América, es necesario tener en cuenta todas estas condiciones que hicieron posible su surgimiento, y que explican en parte la existencia de revistas en español o autodenominadas como americanas, con algunos intereses cercanos, estructurando un espacio en cierta medida común y en buena parte contemporáneas, como las de García Calderón, Darío, Lugones, Sux, y Gustos y Gestos (que tuvo un director menos conocido, el dibujante Leo Merelo). ${ }^{16}$

Como se ha podido advertir hasta aquí, la Revista de América fue un lugar de reunión de los latinoamericanos en París, en el mismo plano en que lo fueron sus domicilios ${ }^{17}$ y los cafés; en su redacción se consolidó un ámbito de sociabilidad o "milieu" (Prochasson 1993), un nucleamiento de intelectuales que tramaron parte de su identidad de escritores en esas relaciones interpersonales. Entre los rasgos de este colectivo, veremos que resultó decisiva su definición identitaria continental, que desplazó en algo el ethos modernista, más centrado en la búsqueda formal o poética. De este modo, en tanto espacio físico, la redacción de la revista hizo posible el contacto entre individuos con orígenes geográficos cercanos y experiencias

${ }^{15}$ Sobre la colonia hispanoamericana en París, ver Fey (1996).

${ }^{16}$ Leo Merelo figura como director de Gustos y Gestos (un insoslayable eco al semanario porteño Caras y Caretas) cuyo título completo era "revista quincenal ilustrada artística, literaria, moda y actualidades" que se publicó entre 1910 y abril de 1911. Un dato significativo es que Merelo aparece desde el inicio de Mundial Magazine como director artístico, por lo que es posible conjeturar que la revista de 1910 fuera un emprendimiento anterior de los hermanos Guido. Evidentemente, esperaban cubrir un nicho en el mercado de publicaciones destinadas a un público general hispanohablante, y capaz de circular tanto en la capital europea como en otras ciudades del nuevo continente.

${ }^{17}$ En un retrato de "Manuel Ugarte" (Sux 1911) enviado a la revista anarquista argentina Ideas y figuras. El periodista y escritor anarquista argentino Alejandro Sux evocó la sociabilidad literaria de los latinoamericanos en la capital francesa, y describió la casa de Ugarte como la "meca literaria" de los jóvenes desterrados. El contacto asiduo entre ellos puede verse también en la correspondencia de Darío o en los bleus intercambiados para darse cita en el mismo día en los domicilios o cafés parisinos (se conservaron los del archivo de Manuel Ugarte, por ejemplo). Sux residió en París entre 1910, cuando fue deportado desde Buenos Aires (por aplicación de la Ley de Defensa Social que perseguía a los militantes políticos) y 1920. Fue, por un período, secretario de Rubén Darío y fundó también una revista, Ariel (1912-1913), en la que publicó un viejo escrito de Darío sin su autorización, lo que le valió una ruptura con el poeta. 
comunes. Pero sobre todo, contribuyó a estructurar ese ámbito o entorno, sociológicamente homogéneo dada la misma pertenencia social (las clases altas, o medias sin dinero pero con capital social) y la coincidencia estatutaria de los escritores, y con afinidades electivas compartidas (su identificación con la renovación estética e intelectual del movimiento modernista). Finalmente, sus integrantes también compartían disposiciones para desarrollar un tipo reciente de actividad profesional que intentaba abarcar tanto las letras como el periodismo, y convertirla en su principal sustento.

Además de esta dimensión colectiva, que hace de la revista una formación en el sentido williamsiano (Williams 1977), es necesario considerar su otra realidad, dada por el proyecto editorial e intelectual que ella encarna y materializa. Precisamente, en tanto realidad discursiva (Pluet-Despatin), de proyecto editorial/ intelectual, alcanza una existencia más efectiva y sólida que el efímero lugar de sociabilidad, de contornos más borrosos. En el caso de la Revista de América, esta forma editorial contribuyó a consolidar el aspecto intelectual de la sociabilidad trabada en ese grupo o ámbito social. Es así como llegó a configurar en sus páginas el espacio simbólico de lo continental/latinoamericano y a sellar su constitución, no sólo enunciando un discurso latinoamericanista -que analizaré más adelante- sino reuniendo las firmas interamericanas en el espacio concreto de la publicación, o también a través de la estructuración de diferentes secciones dedicadas a las letras de cada país del subcontinente.

Hasta aquí, teniendo en cuenta la consideración de la revista esbozada por PluetDespatin y desarrollada por las investigaciones de De Marneffe, en tanto doble entidad, esto es como formación-articulación interpersonal y como proyecto editorial- discursivo, me he detenido en una primera dimensión de la revista, al describir el entorno de los latinoamericanos en París. De este modo, mi propósito fue, por un lado, echar luz sobre las circunstancias en que se dieron sus vínculos y disposiciones y, por otro lado, comprender algunas decisiones "editoriales" de la revista (como la elección de los colaboradores). Partiendo de estos primeros resultados, me ocuparé ahora de examinar la segunda dimensión de la revista, su forma editorial, un híbrido entre literatura y prensa, cuyas características intentaré describir en detalle. Desde la dimensión discursiva-editorial de la revista, es posible considerar también el punto de enunciación, colectivo, de esta publicación (De Marneffe), que examinaremos en la intervención liminar pero también en otras estrategias de composición como la inclusión sistemática de notas biográficas, las secciones particulares dedicadas a las letras nacionales o la referencia a la misma revista por parte de los colaboradores, que establece interlocuciones que legitiman el proyecto y aporta cohesión al conjunto. 


\section{Mediaciones críticas: "América está al orden del día"18}

La Revista de América publicó mensualmente un total de 28 números desde junio de 1912 hasta septiembre de 1914, cierre que coincidió con el inicio de la Primera Guerra Mundial. Francisco García Calderón, su director, convocó para el comité de redacción a su hermano Ventura y a Hugo Barbagelata. ${ }^{19}$ Desde el punto de vista del formato, se trató de una edición muy cuidada, con buena calidad de papel, una tapa de color ocre-mostaza y en formato in-cuarto. En sus rasgos formales, se acercaba claramente al libro, y menos al diario, como solía suceder en cambio con las publicaciones "políticas", de combate o con vocación "popular".

Otro elemento, que otorga a esta revista un aspecto libresco, está dado por la numeración que se prolonga a lo largo de tres números, hasta alcanzar las 400 páginas. Tal continuidad contribuye al estilo "serio" de la revista y refuerza su vocación de ser antología o compendio de ensayos, poemas y crónicas (los tres géneros predominantes en ella). Además, al imponer una continuidad superpuesta al orden cronológico, este tipo de páginación marca una distancia respecto del mandato de una actualidad más inmediata. Así, mientras no deja de aspirar a una función periodística al inscribirse en una contemporaneidad más abierta (dada por su periodicidad mensual) que la del libro, y al difundir la novedad y las producciones intelectuales y literarias recién elaboradas y puestas a circular, la publicación se presenta sin embargo como un producto visual y materialmente equiparable al libro. ${ }^{20}$ No figuran datos sobre la cantidad de ejemplares por número. En cuanto al costo del abono anual, de 12 francos y 15 en "América latina y el extranjero", es mayor que el de la Revue des Deux Mondes ${ }^{21}$ que ocupaba una clara posición hegemónica en el mercado francés de revistas. Más allá de esta diferencia en los costos, el abono anual de la revista que nos ocupa no resultaba excesivo si se

${ }^{18}$ Revista de América, no13, "Revista de revistas", p. 163.

${ }^{19}$ En el número 1 aparece al pie de una página la mención del gerente: "Le Gérant : Albert Morisson" (p. 102), otro indicio de la impronta formal y profesionalizante del proyecto.

${ }^{20}$ La revista comparte las características materiales de las revistas francesas más visibles de París, y más leídas en el continente americano. Así, además del tamaño, el criterio de numeración coincide con el de estas revistas culturales francesas de gran divulgación o con otras denominadas independientes: la paginación abarca varios números, llegando incluso hasta las 900 páginas en algunos casos, tanto en La revue des Deux Mondes como en La Plume y el Mercure de France.

${ }^{21}$ Cada número de la Revue des Deux de Mondes se vendía a 8 francos, pero contaba con 15.000 abonados en 1910 y 40.000 en 1914, una cantidad excepcional en el período (Mollier 2002 ; Loué 2002; Martin 2002). A título ilustrativo, téngase en cuenta que en 1913 el precio de las ediciones populares de libros era de 3,50 francos, mientras que cada tomo en una colección de obras completas en la editorial Flammarion se vendía a 7,50 francos (Mollier 1988 : 479). 
lo compara con el Mercure de France, que contaba con abonados en América y cobraba 30 francos por un abono anual desde el extranjero, y 25 en Francia. Es probable que la iniciativa de García Calderón haya encontrado un impulso en la aparición de Mundial Magazine, en 1911, que Darío había aceptado dirigir, como se sabe, por motivos de subsistencia, pero sin dejar de incorporar al proyecto el objetivo de reunir colaboraciones de escritores latinoamericanos. ${ }^{22}$ De perfil más comercial, esta revista miscelánea apuntaba a un público lector, latinoamericano e hispanohablante que la revista de García Calderón podía aprovechar para su tirada mensual.

En afinidad ideológica con la distinguida Revue des Deux Mondes, la Revista de América reúne en su aspecto material los rasgos serios y elevados con los que pretende ser recibida. De hecho, existe un vínculo concreto entre ellas, dado que la revista latinoamericana contó con la colaboración de una de las firmas más renombradas de su homóloga francesa, la del publicista francés Firmin Roz. Estas características son reveladoras de la distinción que desde sus inicios asumió en su identidad la revista de García Calderón. Se trató, en este sentido, de una publicación de las nuevas generaciones de las elites intelectuales del continente, y destinada a esas elites sociales o políticas. Situándose a espaldas de la cultura de masas, cuya expansión era ya observable no sólo en Francia sino en las principales ciudades latinoamericanas, declaraba un afán de ser difusora y productora, o "exponente de la cultura americana de hoy" según su propia definición aparecida en el $\mathrm{n}^{\circ} 7$ (1912). Ahora bien, precisamente, a la vez que buscó reunir "notables firmas" $\left(\mathrm{n}^{\circ} 7\right)$ entre sus páginas y dirigirse así a los pares, no dejó de desplegar estrategias de divulgación cultural destinadas a un público más amplio que los interlocutores escritores e intelectuales. Tal pretensión aparece nombrada en términos de "propaganda de cultura" desde el $n^{\circ} 1$ :

En esta Revista, escritores de gran competencia estudiarán continuamente el movimiento filosófico, artístico y literario de Europa. Si algo falta a nuestra joven literatura es información: abundante, varia, hemos de darla a un público sutil que quiere saber, que busca, entre tanteos, rutas intelectuales.

[...] Pero no sólo seguiremos el movimiento de las letras europeas. Hemos pedido a selectos espíritus de cada república americana noticias sobre el desarrollo intelectual de esas naciones. Será ésta la más preciada novedad de la Revista de

${ }^{22}$ Alcides Arguedas recuerda en sus memorias la siguiente conversación con Darío sobre Mundial: "Si he aceptado tomar la dirección de ella es porque deseo agrupar lo más saliente de la intelectualidad de nuestra América. Los propietarios me presentaron una enorme lista de autores franceses y yo la he desechado, porque si quieren hacer una revista para América, americanos la han de escribir. Y también españoles [...]. Por lo demás, los Guido [...] son muy ricos y me pagan bien. Además de mi sueldo como director, tengo el veinte por ciento de la venta..." (Arguedas 1959: 645). 
América: por ella podrá el lector conocer la evolución de las letras ibero americanas, de México a Buenos Aires $\left(\mathrm{N}^{\circ} 1,1912\right)$.

Esa intención de interpelar a un público "sutil" hace que la publicación no desdeñe la publicidad, tanto más cuanto que su director aspiraba a crear un órgano de cultura que fuera capaz de insertarse en el mercado de las revistas destinadas a consumidores latinoamericanos, y de competir quizá con las ventas de las revistas francesas en el continente. En este sentido, la propaganda puede contener datos valiosos para inferir el tipo de lectorado al que se apunta la revista de García Calderón, que incluye pocos pero significativos anuncios (no más de tres por número). Todos los anuncios publicitarios, de tiendas francesas, están sin embargo en español y contienen una fotografía o ilustración. Esto refuerza el sentido de la interlocución, orientado a un público bien específico, las clases altas del continente, lo que a su vez se evidencia en el tipo de productos publicitados: artículos suntuosos de casas de sastres francesas o inglesas, productos industriales (por ejemplo, la publicidad de armas Mauser), o servicios de transporte marítimo. Otros, incluso, apuntan a las actividades financieras de los viajeros, como es el caso de las publicidades del Banco español del Río de La Plata y su sucursal parisina, en la contratapa.

La voluntad divulgadora de temas de interés para un lectorado culto también puede leerse en las modificaciones que va realizando la revista, orientadas a extenderla más allá de los pares, hacia un público amplio. Así, aquellas secciones que en los primeros meses de la revista estaban dedicadas a las letras de los distintos países y podían apuntar al sector restringido de la vida literaria, e interesar ante todo a los críticos y escritores, se volverán más esporádicas apenas siete meses después de su aparición, hasta quedar reducidas a uno o dos países por número. En su reemplazo, se opta por crónicas de cultura general, dedicadas a sintetizar las últimas novedades en materia de economía latinoamericana, política internacional, o música contemporánea francesa. Significativamente, un mes antes de introducir los cambios, la revista los justifica y anticipa las "transformaciones" a los lectores, en una volanta de papel rosado y menor tamaño que se agrega al número 8: se incluirá un suplemento ilustrado "de la más amena actualidad, a cargo de nuestro colaborador Ventura García Calderón". Además, la dirección promete que "artículos económicos darán a conocer la interesante faz agrícola e industrial de nuestra América", mientras que "nuevas crónicas de música y pintura alternarán con las literarias y filosóficas". También anuncia que a partir del $n^{\circ} 9$, de enero de 1913, publicará los "juicios que ha merecido esta Revista en la prensa americana".

Como se ve, la revista presenta un dinamismo en su construcción, dado por la búsqueda de nuevos rumbos formales y editoriales (aunque no ideológicos) con el fin de atraer lectores. Es por eso que el sentido de su proyecto editorial no debe entenderse como exclusivamente testimonial o de contenido, sino marcado por una intensa interpelación al público susceptible de consumir su oferta cultural. En cierto 
modo, se trataba de acumular capital simbólico entre los círculos intelectuales hispanoamericanos, en beneficio de su director $\mathrm{y}$, en menor medida, de sus colaboradores, al tiempo que la orientación hacia el mercado de consumidores pertenecientes a las elites hispanoamericanas, de paso por Europa o que habitaban las ciudades del continente, podía ser una fuente de sustento para la publicación que pagaba a sus colaboradores. La política de acercamiento a un público culto y de clase alta se intensifica con la creación de un suplemento ilustrado que estará dedicado, como lo sugiere el mismo título, a "La actualidad". Este señala un agregado mundano en la revista y se presenta bien demarcado del cuerpo de la misma no sólo porque sus páginas poseen una numeración aparte sino en su aspecto gráfico, al incorporar ilustraciones que desde un punto de vista semiótico, la alivianan. Además, la delimitación se ve reforzada por el contraste entre la austeridad visual del cuerpo de la revista y esas ilustraciones. En lo temático también se distingue la lógica más duradera de los artículos disponibles en la revista, respecto del carácter efímero, ajustado a un presente en estado de desarrollo, de las noticias sobresalientes del último mes. En el suplemento, conviven así noticias sobre sucesos recientes de la vida política francesa, con novedades acerca de la escena teatral parisina, $u$ otras más mundanas e impactantes, como la muerte trágica de los dos hijos pequeños de la actriz Isadora Duncan, sucedida en París, crónicas de moda femenina y masculina a cargo de la "Condesa de Falbalas", o una nota de actualidad artística sobre "¿Qué cosa es el Cubismo ?", en el $\mathrm{n}^{\mathrm{o}} 13$, de junio de 1913, probablemente una de las primeras noticias americanas sobre ese movimiento.

De lo estudiado hasta aquí, puede decirse que a la intención de instituirse en revista general, de literatura y política, asumiendo una tarea de divulgación cultural destinada a las elites americanas, se suma la voluntad de convertirse en medio de expresión para los jóvenes escritores del continente. Además de la calidad ya mencionada de los ejemplares, sus elementos gráficos aportan distinción a la revista, tanto en su escasez como en su sobriedad. Así, hasta que aparece el suplemento "La Actualidad", sólo las tapas presentan algún diseño: por un lado, las letras del título, en mayúsculas renacentistas, están en sintonía con el humanismo de la publicación. Por otro lado, en la tapa del primer número figura, sobre un fondo liso, el grabado de una carabela navegando en alta mar. De los números 2 al 11, se reemplaza esa imagen por una guarda que abarca toda la tapa, de estilo Modern Style, que combina formas geométricas romboides, con algún eco de arte indígena andino (en los colores y puntos). Ahora bien, a partir del $\mathrm{n}^{\mathrm{o}} 12$, cuando se acerca el primer año de su existencia, la revista retoma la carabela sobre fondo liso en la tapa como si se buscara dar coherencia y unidad al proyecto. La elección de la imagen, además de ser deliberada, por supuesto, aparece explícitamente justificada: en la última página del suplemento, justo antes de la página inicial de ese número, en simetría con el retrato del poeta colombiano "más grande de América" José 
Asunción Silva (de quien anuncia la publicación de un poema inédito en esa entrega), se reproduce el mismo grabado. Y lo acompaña una suerte de leyenda:

Quisiéramos hacer de la carabela que ilustra hoy la Revista, el símbolo y el leitmotiv de nuestro esfuerzo. También hemos partido a la aventura. Van a bordo soldados y misioneros que no buscan oro ni catecúmenos, sino un poco más de gloria y de cultura para la "más grande América". Y también, mientras el viento hincha la vela y el mar se enarca, algunos canes en la orilla están ladrando...

Esta leyenda que acompaña el grabado no presenta firma, pero su enunciador expresa con una voz en plural la intención de la Revista. Cumpliendo una función de manifiesto segundo de la revista, la descripción de la carabela dice mucho sobre el lugar que la revista le asigna al intelectual, cifrado en la metáfora de los "soldados y misioneros". En el rechazo de cualquier fin materialista para su "aventura" intelectual, predomina una imagen profética, en la referencia a estos nuevos evangelizadores culturales. Es posible advertir a su vez una negación de cualquier fin que no sea espiritual, y una posición solitaria de pugna frente a la adversidad (en la imagen de los canes que ladran), que contiene nítidos ecos rodonianos. A ellos también alude el superlativo con el que se define al continente, que expresa ambiguamente tanto un deseo superador, como una invitación a contrastarlo con "otra" América, no latina. Ahora bien, no podemos dejar de leer en el fragmento, una autofiguración de la propia lejanía de los editores respecto de sus países de origen. Tampoco es ajeno al símbolo de la carabela elegido, la posición mediadora "entre dos" mundos que caracteriza su intervención intelectual. Finalmente, revela el paradójico eurocentrismo de la revista, en tanto asume como propio un punto de partida e incluso un tipo de embarcación europeos, al tiempo que se enuncia como representativa de la cultura americana.

Un año antes, en el numero inicial, el manifiesto liminar titulado "Un acto de fe" aparecía firmado lacónicamente por "La dirección". La ausencia explícita de centralidad de su director, que no publica ninguna colaboración, puede asociarse a la pretensión de seriedad y especialización que he venido analizando. Este carácter impersonal también redunda en el tono sentencioso que abre el "Acto de fe", cuyo título anticipa una expresión de deseos y aspiraciones de una obra a realizar, obra intelectual a cargo de los jóvenes, combinada con la afirmación de principios que podríamos sintetizar como latinistas, por un lado, y americanistas, por el otro. Veamos cómo se articulan.

En la estela diagnosticadora característica de los discursos de fines del siglo XIX y comienzos del nuevo siglo en América Latina, ${ }^{23}$ las palabras iniciales de la revista

${ }^{23}$ He analizado este aspecto retórico del ensayismo de comienzos de siglo en mi tesis sobre el Itinerario intelectual y literario de Manuel Ugarte. Ver también Merbilhaá 2010 y 2011. 
que nos ocupa señalan que " diversos signos morales revelan que la América Latina va a entrar en una nueva etapa saludable": muy recientemente han quedado atrás las "discordias" y "en el orden intelectual, el aislamiento" y los enunciadores observan que "oscuras fuerzas van cambiando hoy el drama de la historia" hacia la unificación de los países del continente (en torno a la tradición hispana o a la latina), condenando "el caudillismo, la política estrechada por el horizonte local, la turbia retórica que esconde bajas codicias". Es posible advertir aquí un verdadero consenso arielista en torno a dos principios políticos centrales: la exigencia universalista, fundada en los valores del humanismo, por un lado, y el rechazo del plutonismo, por otro. En ese mismo sentido, el manifiesto opone en su cierre, una moral del "estudio, la tolerancia, la serena razón", frente a la "violencia anárquica".

De ese diagnóstico en torno a una etapa nueva que es necesario apuntalar, surge el fin de la Revista, su misión intelectual de profetizar la unión y contribuir a ella:

Una juventud atenta al rumor del porvenir ha escuchado la promesa mesiánica. ¿Vendrá el director intelectual en quien todos esperan, tendrá el nuevo mundo latino, como la Germania dividida, un Fichte que anuncie el gran Renacimiento?

Preparemos, por la unión de los elementos intelectuales, la gloriosa epifanía. Tal es el objeto de esta Revista. Tiende ella a agrupar a los escritores ibero americanos, sin parcialidades de cenáculo, sin celos de región, en amplia confraternidad, en tenaz propaganda de cultura. Amigas voces la piden, comprenden que la dispersión es flaqueza y que ha llegado la hora de la concordia moral. Sin ufanarnos del resultado obtenido, podemos decir que nos han ofrecido su concurso los mejores escritores latinoamericanos. Pertenece esta Revista a la élite intelectual de ultramar. Este primer número lo revela. ${ }^{24}$

Como se ve, a fines tan elevados parecen corresponder ejecutantes de igual altura, de modo que en un mismo movimiento, el manifiesto afirma los objetivos de propagar un nacionalismo apenas ensanchado, dilatado a nivel del subcontinente, y la identidad de un colectivo intelectual selecto que se autodesigna el mandato de anticipar esa unión, en lo intelectual, y de darle su fundamento moral (ideológico), político. No puede dejar de observarse un detalle revelador en esta definición identitaria del colectivo intelectual, que acusa un eurocentrismo naturalizado, al nombrarse a sí mismo como "de ultramar", locución enunciada desde un punto de mira con evidente base en el continente europeo... Ese locus de enunciación legítimo (en la cultura europea) es a la vez, paradójicamente, el lugar de producción de la Revista de América. En efecto, se relaciona con la experiencia misma de los intelectuales que fundan la revista o que gravitan en torno suyo, de allí que el manifiesto fundacional destaque la coincidencia fortuita de ideas y objetivos de los "Espíritus que llegan a París de opuestos confines, de México y del Plata, de

\footnotetext{
${ }^{24}$ Revista de América, a.I, nº 1 , junio de 1912, pp. 1-3.
} 
Venezuela y Chile". El discurso también refuerza la idea de una pertenencia "espiritual" común a los editores, colaboradores e interlocutores de la revista, que corresponde por supuesto a su mismo origen social. Así, abunda el vocabulario de lo excelso, elevado, refinado, que se distingue de lo mediocre o de "los gustos del ignaro público". Los colaboradores son "selectos", siempre "cultos", y la revista presenta entonces su misión, destinada a colmar la "falta de información", para brindarla a "un público sutil que quiere saber, que busca, entre tanteos, rutas intelectuales" ("Un acto de fe", p. 2).

Ahora bien, mientras el principio unionista encuentra su fundamento, como hemos visto, en la acción moral de la que son capaces los espíritus selectos, el ideal que lo mueve, la marca identitaria que justifica la unión, se define en torno a la latinidad -siguiendo el mandato arielista, y también el racialismo hegemónico en el período-: la voz de la revista se refiere dos veces en su manifiesto de apertura, al "nuevo mundo latino" y elabora un relato de origen europeizante, muy cercano a las tesis de Les démocraties latines de l'Amérique de Francisco García Calderón, cuyo año de publicación coincidía con el nacimiento de la revista. Pero en su presentación, las palabras liminares omiten el "problema de la raza", uno de los últimos capítulos de ese ensayo : si no se detiene en la herencia indígena, mestiza o africana, es seguramente porque el discurso inaugural de la revista podía prescindir de los requisitos del género ensayístico positivista que establecía un abordaje de los componentes raciales para definir la nacionalidad y adivinar su evolución, en el contexto de la modernización de las repúblicas latinoamericanas. Para el manifiesto inaugural, bastaba, en efecto, considerar exclusivamente a los componentes latinos que, según el paradigma etnocéntrico, estaban en condiciones de determinar los aspectos morales y espirituales de aquellas sociedades. Más aun, la revista no sólo enuncia su latinidad sino que se propone realizarla, en el sentido más performativo: ${ }^{25}$

De España, de Francia, de Italia, recibiremos selecta colaboración : será así este órgano revista latina, fundirá harmoniosas (sic.) tradiciones. Debemos a los pueblos que ciñe el Mediterráneo hombres, glorias, ideales. Nuestra herencia no sólo es española y portuguesa: a la arrogancia, al individualismo ibéricos, se han agregado la elegancia francesa y el fervor italiano. Más complicada el alma americana que la de los primitivos dominadores del nuevo mundo, ha de aceptar todo intelectual esfuerzo esa riqueza de matices y de influencias que anuncia ya la gran raza del porvenir ("Un acto de fe", p.2).

25 Esta intervención latinista se verifica en la centralidad que ocupa el tema en un paratexto tan visible como el de la contratapa de cada número: "Cuenta con la colaboración de notables escritores de América, Francia, España e Italia. Aspira a presentar en síntesis el esfuerzo intelectual de los países latinos de ultramar". 
Debe decirse que este mismo movimiento argumentativo de definir en clave espiritualista el alma americana como latina por herencia y por propia evolución, encierra un gesto igualador entre las naciones del nuevo continente respecto de Occidente, aunque no deje de ser limitado, al sostenerse dentro de la legitimidad de la cultura europea. Como sea, en otros aspectos, resulta significativa esta concepción disimétrica tan predominante, que tenían los intelectuales latinoamericanos acerca de las prácticas de pensamiento en nuestras naciones. Por ejemplo, cuando el manifiesto alude a las producciones artísticas, literarias y ensayísticas europeas, el término "cultura" se usa para remitir no sólo a las obras de todos lo tiempos sino también a las del presente. Sin embargo, cuando se refiere a la producción continental, que merecerá incluso la distinción de la revista, el sentido de "cultura" pasa a tener un carácter inconcluso, traduciendo una concepción de los desarrollos intelectuales y artísticos locales como formas inacabadas: son "tanteos", "esfuerzoo" y "energías" en estado evolutivo, y nuestra literatura es "joven". Del mismo modo, los "genios" también están por venir y deberán ser creados "mañana" por la "raza ardiente, curiosa, liberal" que ayer creó "caudillos y libertadores" ("Un acto de Fe"). Esta concepción de la cultura inacabada funciona, estratégicamente, como una solución frente al debate en torno al "vasallaje intelectual" respecto de los modelos europeos. Así, la "Dirección" parece prevenir posibles refutaciones o reproches ante una excesiva sujeción a la cultura europea, y para eso, menta el debate en torno al modernismo, pero postergar la opción por uno de los términos del dilema amparándose en el hecho inapelable para los parámetros evolucionistas de la época, de que la cultura americana, aun en formación, necesitaba ese "beneficio de cultura", cultura forcément europea. Estas claras marcas de una dialogicidad interna con el modernismo son reveladoras del modo en que los debates de la revista gravitan todavía en torno a ese movimiento. De allí la petición de principios, dada por la proclama del axioma independentista, que puede interpretarse como una respuesta implícita a las refutaciones de posibles contradictores, que intenta disipar:

La aceptación incondicional de extranjeros modelos conduce al vasallaje intelectual. Preguntóse una vez un escritor eminente, Paul Groussac, que hasta cuándo viviríamos de copias, seríamos habitantes de Mimópolis. La imitación ha de preparar la futura invención, la originalidad necesaria. Somos defensores de la autonomía literaria, del americanismo en el pensamiento y en las letras. No se confunda, sin embargo, novedad con ignorancia ni en nombre de una intuición semi-divina se renuncie al beneficio de cultura. ("Un acto de fe ", p. 2)

Finalmente, el carácter serio y meditado, no improvisado, de la publicación -al que me he referido anteriormente- está en consonancia con el ethos arielista en torno al "estudio" y la "serena razón", y también puede observarse en el manifiesto 
inaugural, especialmente en el modo en que allí se anticipan con nitidez las líneas editoriales de los números sucesivos. ${ }^{26}$ En primer lugar, la dirección anuncia las colaboraciones de la "élite intelectual de ultramar", por un lado, que serán convocadas, realizándose así el acto de $f e$ en la unión: artículos de autores reconocidos sobre temas varios, que no se detallan. Por otro lado, se sumarán las colaboraciones de autores de países "latinos". En segundo lugar, la revista promete otro tipo de secciones, dedicadas la crítica literaria y artística, y aquí también se subdivide, en cierto modo, en secciones de crítica sobre las novedades europeas, por un lado, y en otras dedicadas a la "evolución de las letras ibero americanas" (p.3). ${ }^{27}$ Esa será, precisamente, la estructura que tendrán los números, con leves variaciones como la incorporación, ya mencionada, del suplemento ilustrado, o el abandono de las secciones regulares dedicadas a las letras nacionales. A continuación, examinaré algunas de las estrategias desplegadas a través de las distintas secciones de la Revista de América.

Las colaboraciones ocupan la mayor parte de las páginas de la revista y no llevan el encabezado de una sección. Como lo indica el índice, las secciones se reservan para la segunda parte, en que se reseñan las Letras de distintos países (que van variando de un número a otro). Si nos detenemos en los autores de los primeros números, enseguida se observa que la revista sale a la vida pública con todos los avales posibles, al incluir firmas consagradas que contribuyen a la legitimidad de la revista que se autoproclama como representativa de la juventud intelectual de América. Pero esta transferencia de capital simbólico implica al mismo tiempo una adscripción estética, que sitúa claramente a la revista en la reciente historia renovadora del modernismo. ${ }^{28}$ De hecho, desde su mismo título se advierte un eco de la revista homóloga que Darío había dirigido en Buenos Aires casi veinte años

${ }^{26}$ Puede verse esta faceta organizada de la revista, desde sus comienzos, en el modo en que anticipa en varias oportunidades, en un número, algunos de los artículos que serán publicados en el siguiente, ya sea en pequeñas volantas o en las contratapas. Leemos por ejemplo: "En los próximos números publicaremos artículos de los señores José E. Rodó, Carlos Reyles, José Ingegnieros, Carlos A. Villanueva, B. Sanín Cano, Alcides Arguedas, Enrique Pérez, Pedro Henríquez Ureña, Manuel Gálvez (hijo), etc., etc.” ( $\left.n^{\circ} 1\right)$.

${ }^{27}$ Aquí también puede observarse la relación con el modernismo, en la tendencia a historizarse y a describir su propio "movimiento de las letras".

${ }^{28}$ Una interesante huella de la voz de la revista puede rastrearse en las noticias biográficas sobre cada colaborador, que aparecen al concluir cada artículo. La relación con el modernismo, legible en el poema de Darío que abre el primer número, queda reforzada por la noticia que la revista, en su voz impersonal, le dedica: "No es necesario presentar a Rubén Darío: es el Precursor (sic), el maestro. Dos generaciones le deben la lírica iniciación. Al fundar una revista americana, le hemos pedido que honrara la primera página con el bello tríptico publicado, como solicitaban de los antiguos paladines el espaldarazo los nuevos caballeros en los gloriosos años de la gesta feudal". (a.I, no 1, p. 6). 
antes. En el primer número, además, Rubén Darío da su apoyo al proyecto al ofrecerle su "Tríptico de Nicaragua", cuyas reminiscencias íntimas de la tierra natal dialogan con la vocación americanista de la revista. Las demás firmas también parecen destinadas a dotar de prestigio a la publicación: Gómez Carrillo, el académico y diplomático brasileño Manuel Oliveira Lima, el historiador José de Astorga y el joven poeta mexicano Amado Nervo. En el número 2 se incluyen colaboraciones de José Ingenieros, el más reconocido de los ensayistas, de Sanín Cano y Alfonso Reyes, y ya se anuncia un artículo de Rodó que aparecerá en el tercer número, junto a la colaboración del amigo del director, el peruano José de la Riva Agüero.

Una particularidad de la revista merece nuestra atención pues participa de la estrategia de antologización de las producciones intelectuales del subcontinente. Se trata de las noticias biográficas que se incluyen como cierre de cada colaboración, que están enunciadas por la misma voz impersonal asumida por la dirección de la revista (firmante de las palabras liminares). Estas noticias no se limitan a brindar datos sobre su autor (y, en ese sentido, no son exhaustivas), sino que seleccionan una información afín a los valores que sostiene la revista: indican el nivel de consagración de los autores seleccionados, en sus países respectivos, realizan un breve señalamiento del tipo de actividad intelectual ejercida por el autor, subrayan su "humanismo" o su contribución al ideario americanista, lo que por supuesto reafirma la profesión de fe de la propia revista. ${ }^{29}$ En estas notas puede leerse la intervención de la revista, que cumple un claro rol performativo antes que de combate político, ideológico en torno a un conjunto definido de ideas, al antologizar a través de ellas la vida intelectual latinoamericana. De este modo, la revista ejerció, en la práctica, la "deseada unión de los elementos intelectuales" a través de la publicación sistemática de estas noticias biográficas dedicadas a cada nuevo colaborador, desde el primero hasta el último número. Pero además, ellas son el lugar en que se forja una identidad común a la revista y a los colaboradores, y se reafirma el elitismo analizado anteriormente, de allí que afirmen por ejemplo que "Nos honra mucho el Sr. Verissimo al encargarse de esta sección a la que trae todo su prestigio literario. Crítico eminente [...] es su colaboración un don exquisito para una Revista que inicia sus tareas" $\left(\mathrm{n}^{\circ} 1, \mathrm{p} .91\right)$. Por último, las noticias son también la ocasión para consagrar a los "jóvenes": Ángel de Estrada, Manuel Gálvez, Amado Nervo, Alfonso Reyes, Pedro Henríquez Ureña entre muchos otros ("en folletos de crítica sutil, en versos de exquisita harmonía (sic), en aplaudidas

${ }^{29}$ Así, por ejemplo, se presenta a Gómez Carrillo como "Admirado en Francia, en España, en América [y] maestro de gracia, de ironía, de prosa musical, para la nueva generación americana" ( $\left.\mathrm{n}^{\mathrm{o}} 1, \mathrm{p} .12\right)$; Oliveira Lima es "una de las más notables figuras del Brasil moderno" (p. 25). 
conferencias de cultura, ha revelado vigorosa personalidad este joven escritor dominicano [que] aspira a dar a su obra cívicas proyecciones" $-\mathrm{n}^{\mathrm{o}} 12, \mathrm{p} .40$ ).

Otra estrategia editorial a través de la cual la revista puso en práctica la unión intelectual latinoamericana fueron las secciones fijas dedicadas a reseñar las literaturas nacionales. En ellas los lectores podían conocer las novedades editoriales de al menos dos países de Centro y Sudamérica por número. Uno de los colaboradores de esta sección, Key Ayala, percibió exactamente el valor de ese acto al destacar, en la primera entrega de "Letras venezolanas" $\left(\mathrm{n}^{\mathrm{o}} 12\right)$, el:

\begin{abstract}
Signo sobresaliente de la Revista de América de atender a esas manifestaciones locales [dentro de la patria continental y de la raza] por la sección de letras señalada a cada país de América y reflejar el pensamiento americano en su unidad $\mathrm{y}$ en su variedad, en un haz de luz que todos queremos y esperamos que sea blanca, luz blanca de estrella que endereza los pensamientos al ideal, luz blanca de sol en donde van mezclados y palpitantes todos los agentes de la vida.

¿Es en homenaje a la buena orientación de La Revista por lo que nos detenemos en fundar esos proloquios? Sí... (n ${ }^{\circ} 12$, p. 76$)$
\end{abstract}

Las secciones ponen además en evidencia el lugar otorgado a la crítica en la revista. Allí reside, en efecto, su modernidad, su modo de "estar en el siglo" pues se sabe que fue en las últimas décadas del siglo XIX cuando se consolidó la figura del crítico como mediador autorizado entre los escritores y un lectorado más amplio y diversificado, tal como han analizado, entre otros, Terry Eagleton, en Gran Bretaña y Christophe Charle en Francia. ${ }^{30}$ En el caso de los latinoamericanos, los mismos contemporáneos relacionaron la aparición de este tipo de actividad pública, en los

${ }^{30}$ Resulta pertinente para nuestro análisis la figura del "hombre doble" (productor y a la vez crítico-legitimador de otros escritores) analizada por Charle (1998: 89-94) como emergente del proceso mencionado. El autor analiza, en el París de fines del siglo XIX, que la necesidad de filtrar el reconocimiento del valor literario de las producciones, era un modo de evitar que éste dependiera del puro éxito ante el público, como venía sucediendo, de hecho, como consecuencia el desarrollo de la industria editorial y de la prensa. Si esta situación había implicado una fuente de emancipación para los escritores, en el marco de una desproporción entre la "capacidad de lectura del público" y el crecimiento de la oferta de obras, también dio lugar a la aparición de figuras mediadoras entre público y producciones. Así, el siglo se fue consolidando como la era de la crítica, dado que cada vez más las obras "legítimas", esto es, las que respondían a los criterios dominantes de valoración literaria, podían acceder a un público ilustrado solamente si pasaban por la sanción crítica de diarios y revistas, que sancionaban la suerte de una obra, reduciéndose notablemente otras prácticas tradicionales del circuito alto, donde los escritores se hacían conocer directamente y en ámbitos privados, como la lectura en los salones, la compilación de poemas de varios autores destinados a un lectorado reducido o la sanción por parte de la Academia. 
medios de comunicación, con el desarrollo intelectual de sus sociedades. Podemos verlo, por ejemplo, en la evaluación de uno de los críticos más activos del período, el chileno Francisco Contreras, quien estuvo a cargo de la sección "Lettres hispanoaméricaines" del Mercure de France desde 1911 hasta su cierre, en 1915, sucediendo a Eugenio Díaz Romero : en su libro publicado en París en 1920, Les écrivains contemporains de l'Amérique espagnole, Contreras observa precisamente que por el "desarrollo" que había alcanzado en Hispanoamérica, el género contaba entonces con numerosos escritores que cultivaban la crítica "a [la manera] moderna, es decir la crítica comprensiva y de artista", "de literatura, ciencias y artes" y que el iniciador de esta tendencia no había sido otro que Rubén Darío en Los Raros y otras crónicas (Contreras 1920: 55).

Este tipo de críticos es el que asume, en la sección de la Revista de América, el análisis selectivo de los libros publicados en sus países. Por el tipo de intervención que despliegan, responden a la figura de los "hombres dobles" analizada por Christophe Charle: escritores desdoblados entre su actividad -ejercida en el ámbito privado de su mesa de trabajo- por un lado, y el ejercicio público de la crítica, dedicada a consagrar selectivamente a los pares en función de valores literarios legítimos dentro del sector restringido de la vida literaria, distintos de (y distinguidos respecto de) los valores y criterios de consagración vigentes en el mercado y la gran prensa. De hecho, muchos de los escritores que hemos encontrado hasta aquí, si no todos, ejercieron esta doble función de escritura literaria y crítica -en crónicas, prólogos y ensayos, como ha analizado Julio Ramos en su libro fundamental- (Ramos 1989).

En las páginas de esta sección, como también en la composición editorial de cada número, es posible observar el pasaje progresivo de la construcción identitaria latinoamericana vinculada a la promoción del modernismo y sólo a cuestiones literarias, hacia preocupaciones americanistas generales, a mediados de la primera década del siglo XX. En ese sentido, de manera recurrente en las reseñas sobre las producciones literarias de sus países, los distintos cronistas destacan el aporte común, confluyente, de autores o libros locales al "desarrollo" de su literatura nacional sin evaluarlos en base a sus tomas de posición estética en favor de una escuela. Más aún, desde una mirada alejada del ideal autónomo modernista, se señalan en ellos "problemas de interés social y nacional" o se evalúa su aporte para el "progreso" general. Además, muchas veces los cronistas establecen una posición dialógica respecto del programa de la revista, al marcar la pertenencia más general a "cuanto tenemos de común los hispanoamericanos" ( ${ }^{\circ} 6$, p. 258), tal como leemos en una crónica de Manuel Gálvez.

La sección no está exenta de ser un vehículo en el que puedan dirimirse competencias propias de cada espacio nacional. Un buen ejemplo de esto puede verse en la intervención de Manuel Gálvez, a cargo de las Letras argentinas. En su entrega para el número 6, el autor se ampara en la voz impersonal de La Revista de América, y le transfiere maliciosamente su propio criterio crítico selectivo, al 
explicar su decisión de no reseñar un libro de reciente aparición en Argentina y de distinguir el de Ricardo Rojas: ${ }^{31}$

Entre los libros del semestre, sólo uno vale: Blasón de Plata [...]

Un pequeño libro sobre Nuestros poetas jóvenes alcanzó una venta superior a las flacas ventas normales, y para desdicha futura de su inteligente y estudioso autor, ha sido bastante leído. La Revista de América no puede hablar de Nuestros poetas jóvenes, pese al relativo buen acogimiento que tal libro logró. Nuestros poetas jóvenes tiene tanta importancia como las croniquillas de los diaritos imperceptibles. (LRA, a. 1, $\mathrm{n}^{\circ} 6,251$ )

Más allá del plus de legitimidad que podía aportar al reseñista, este gesto también sella una pertenencia a la revista como colectivo intelectual, en tanto le adjudica un criterio selectivo que en rigor es Gálvez quien había demarcado. Como sea, el criterio revela el ethos elitista compartido por la Revista, que no deja de ser impostado si se tiene en cuenta el hecho de que el libro que resultaba sospechoso a Gálvez debido a su éxito de ventas, no pertenecía a ninguna edición popular sino a la editorial de la revista "Nosotros", y su autor era un coetáneo de Gálvez, nada menos que Roberto Giusti, cuyo nombre Gálvez opta por no mencionar, como si buscara evitar su difusión. ${ }^{32}$

Tal como mencioné anteriormente, la progresiva centralidad que va ocupando la inflexión americanista respecto del ideario artístico modernista también puede leerse en la organización editorial de cada número. En efecto, los índices revelan la vocación no exclusivamente literaria de la revista, que junto a la publicación de poemas, incluye en cada entrega artículos que comparten una temática que podría definirse como cuestiones americanas : en cada número hay artículos sobre historia de América (de Hugo Barbagelata), Simón Bolívar (de Rodó y de Blanco Fombona) o sobre el ensayista y diplomático liberal Juan Montalvo (Blanco Fombona) ${ }^{33}$ o también conferencias como "A Amêrica para a Humanidade" de Manuel de

${ }^{31}$ Se trata de Nuestros poetas jóvenes: revista crítica del actual movimiento poético argentino, de Roberto Giusti, aparecido en la Edición de "Nosotros” en 1911.

${ }^{32}$ Por supuesto, el gesto es también revelador de la competencia ejercida entre pares aun en tiempos de confluencia de fuerzas en pos de la acumulación colectiva de capital simbólico. Pero además ilustra bien la omnipresencia, rayana en la obsesión, que tenía la cuestión del mercado de bienes simbólicos para Gálvez y su generación y más aún, la ambivalencia en torno a las estrategias de atracción de un público lector, al que se optaba por desdeñar preventivamente.

${ }^{33}$ También puede mencionarse el artículo del escritor y diplomático Manuel de Oliveira Lima (de quien el índice de la Revista destaca su pertenencia a la "Academia Brazileira") sobre "O Barao do Rio Branco", el entonces recién fallecido Ministro de Relaciones Exteriores de Brasil durante nueve años (y de cuatro presidentes sucesivos, aclara el artículo). El autor destaca su importancia, más allá de su país, "para las dos Américas". 
Oliveira Lima ; además, se incluye mensualmente una "revista política" referida a asuntos de distintos países del subcontinente, a cargo del chileno José de Astorga, radicado en París. ${ }^{34}$

Resulta destacable, asimismo, la evaluación histórica, retrospectiva, acerca del movimiento modernista al que tiende la revista, que busca expresarse y expresar un colectivo generacional autodefinido por una relación filial con su renovación literaria y de pensamiento. Si bien el propio modernismo, como muchos movimientos de vanguardia, se caracterizó por situar su ruptura en una continuidad histórica, en la revista de García Calderón, varios colaboradores retoman esta perspectiva, desde Rufino Blanco Fombona, hasta Francisco Contreras o los más jóvenes como Pedro Henríquez Ureña. En esta suerte de balance, se advierte una vez más un énfasis en el legado americanista ("criollista") del movimiento, al que se concibe como un imperativo literario a desarrollar en el presente. Pueden citarse, por ejemplo, el llamado de Blanco Fombona, uno de los más asiduos colaboradores, en su artículo "El modernismo literario en América": ${ }^{35}$

Si queremos en América conservar nuestra soberanía de naciones, ¿cuál apoyo más sólido que el espíritu, mantenido en libertad, de los ciudadanos de Hispano América? No abdique nadie, y menos los mejores en inteligencia, de su yo individual. El servilismo y la imitación en el terreno de las ideas preparan, en el terreno de la práctica, a recibir el yugo. Esto va con los hombres de letras y con los hombres de Estado, con los escritores y los legisladores.

[...] El cultivo del yo, el fecundo y noble individualismo, tan de acuerdo con nuestra raza y con nuestra historia, debe ser nuestro norte. No desviemos el individualismo hacia autolatría absurda, sino fortalezcámosla por un sentimiento

${ }^{34}$ Puede citarse asimismo al diplomático ecuatoriano radicado en Suiza Pallares Arieta en su artículo dedicado a Les démocraties latines de l'Amérique de Francisco García Calderón: "Estas ideas propias mías, que no pueden ser miradas sino como la expresión de un pensamiento general tanto en mi patria como en el Perú, las expongo con toda la lealtad del caballero, con todo el patriotismo de ecuatoriano insospechable y con todo el espíritu liberal de la fraternidad americana, en pleno París, centro de la civilización latina, y en $L a$ Revista de América, dirigida por un peruano. [...] Estrechémonos las manos y avancemos al porvenir por el camino de la paz y del trabajo. Y proclamemos también nosotros nuestra doctrina: Hispano-América para los hispano-americanos" ( $\mathrm{n}^{\circ}$ 7, pp. 304-305 subrayado del autor).

${ }^{35}$ El balance del modernismo por parte de la generación siguiente a Darío, que fue también contemporáneo de él, merecerá un trabajo aparte. Me limito a señalar aquí la presencia de esta cuestión a lo largo de la revista, como puede verse en el "Manifiesto a la Juventud literaria de América" de Víctor Pérez Petit ( $n^{\circ} 7$, diciembre de 1912) o en el artículo del español Andrés González Blanco "Los poetas de América" (nº 16, septiembre de 1913). 
generoso de utilidad social, ya sea realizando un sueño de belleza, ya un sueño de dominación.

Saludemos el criollismo que ha dado, o tiende a dar, una patria a nuestro espíritu $\left(\mathrm{n}^{\circ} 8,39\right)$

\section{Conclusiones}

Si hasta fines del siglo XIX los escritores hispanoamericanos solían enviar sus libros a los cronistas españoles esperando que los reseñaran (recordemos, al respecto, la carta de Darío a Luis Berisso, de abril de 1899, en que detalla esos esfuerzos), pues ésa era la vía casi exclusiva para obtener difusión -fuera de los pocos periódicos locales-, en la segunda década del nuevo siglo las condiciones habían mejorado mucho, gracias al crecimiento de las publicaciones especializadas tanto en el continente como en Europa. La Revista de América formó parte, precisamente, de este proceso. Sin duda, el impacto renovador del modernismo y su búsqueda de horizontes internacionales fue decisivo para que los jóvenes que habían llegado a la vida literaria inmediatamente después que los primeros modernistas, buscaran rumbos intelectuales, y laborales, fuera de sus países de origen. La coincidencia de sus experiencias de destierro y de búsqueda profesional dio lugar a la conformación de un ambiente, entorno o milieu de latinoamericanos parisinos, que estableció tempranamente lazos concretos y también de filiación simbólica con Darío, o discipulares con Rodó (aunque fueran casi contemporáneos del uruguayo) e Ingenieros.

Tal espacio o red de pertenencia puede reconstituirse a través del análisis de la Revista de América de Francisco García Calderón, lo que he analizado en la primera parte de este trabajo. En cuanto al proyecto editorial de la revista, he intentado dar cuenta de las distintas estrategias de reunión de las voces de los escritores radicados en Europa, por un lado, y de difusión de las producciones del continente. La publicación fue a su vez un vehículo para consolidar y difundir un discurso latinoamericanista y a la propia figura del intelectual joven, al que se concebía como un pilar imprescindible para la renovación política de las repúblicas del Nuevo Mundo. En efecto, si la revista no respondió a un programa político definido, apostó a una acción moralizadora inspirada en principios liberales en lo político, y espiritualistas en lo filosófico. ${ }^{36}$ De allí el carácter elitista que mostró

${ }^{36}$ En la voz de José Astorga, que ocupa una función importante en la revista dado que colabora en casi todos los números y queda a cargo de la sección "Revista política" a partir del número 2, puede leerse una continua preocupación por el peso que puedan tener las "reivindicaciones populares" (como señala a propósito del "socialismo agrario" de los "revolucionarios del Sur encabezados por Emiliano Zapata" - $\mathrm{n}^{\circ}$ 5, p. 186) o por la "creciente agitación obrera" y el "desarrollo ficticio de un socialismo importado" (en su "Revista política" del $\mathrm{n}^{\circ} 3$, por ejemplo -p. 250). Un rechazo de las ideas revolucionarias, 
tanto en los destinatarios a quienes buscó interpelar, como en los autores y producciones que quiso difundir. En este marco, he intentado analizar el carácter paradójico de su americanismo, que si bien buscó reivindicar la cultura del continente, considerando exclusivamente a la cultura ilustrada, no pudo más que hacerlo en el marco de un eurocentrismo que lo llevó a definir sesgadamente las culturas locales, en base a rasgos identitarios latinistas que omitían o desconocían a otros habitantes de origen indígena, africano o mestizo.

Desde el punto de vista de su acción intelectual, la revista de García Calderón cumplió una función mediadora que resultó decisiva para la modernización y profesionalización de las prácticas intelectuales en América Latina, proceso que a partir del movimiento modernista encontró una de sus claves en los vínculos transnacionales entre escritores provenientes de distintos países del continente. $\mathrm{He}$ intentado analizar tres aspectos distintos de estas mediaciones. En primer lugar, la revista estableció una mediación crítica entre productores y lectores, que constituía una de las instancias de consagración características del desarrollo moderno de las actividades intelectuales. En segundo lugar, medió entre pares, al convocar en sus páginas a los escritores nacidos en distintas partes del subcontinente. Por último, se propuso como mediadora entre las culturales letradas del viejo y el nuevo continente, al publicar en el mismo espacio, análisis referidos a las expresiones artísticas y ensayísticas de Europa y América. En su base, estos análisis se sostenían en una consideración desigual de las producciones latinoamericanas en el que las culturas de Francia y Gran Bretaña aparecían como las más legítimas. Sin embargo, la revista tuvo como uno de sus debates recurrentes el dilema heredado del modernismo, entre imitación de modelos estéticos europeos y creatividad original. En este sentido, la respuesta específica a este dilema puede verse en un doble movimiento de, por un lado, sostener el "beneficio de la cultura" que los llevaba a informar sobre las últimas novedades artísticas europeas, pero, por otro lado, de reivindicar el "desarrollo intelectual" latinoamericano y destacar la "excelencia", o el alto valor estético de las producciones locales que seleccionaba. De este modo, al fundarse en la necesidad de transmisión informativa, de actualidad, la revista abarcó de manera indistinta a Europa y América, concretando en sus páginas (e índices) el acercamiento temporal (en términos de novedades estéticas) entre centro y periferia. En ese rol difusor y selectivo (de la novedad, dentro del "movimiento de las letras europeas" y de cada "república americana", a través de "espíritus selectos" de cada una de ellas, encargados de publicar "noticias sobre el desarrollo intelectual de esas naciones"), La Revista de América afirmó su papel de mediación entre viejo y nuevo mundo.

socialistas, puede verse en otro artículo de Juan Gadea, en el $n^{\circ} 12$, sobre "El socialismo en el Uruguay". 


\section{BIBLIOGRAFÍA}

ARGUEDAS, Alcides.

1959 Obras Completas, tomo 2. Madrid: Aguilar.

CHARle, Christophe.

1998 Paris fin de siécle. Culture et politique. Paris: Seuil.

DE MARNEFFE, Daphné.

2007 Entre modernisme et avant-garde. Le réseau des revues littéraires de l'immédiat aprés-guerre en Belgique (1919-1922). Tesis de doctorado, Université de Liège.

DARÍO, Rubén.

2000 Cartas desconocidas de Rubén Dario. Managua: Academia Nicaragüense de Lengua.

DEGIOVANNI, Fernando.

2007 Los textos de la patria. Rosario: Beatriz Viterbo.

GONZALES, Osmar.

2008 "Las formas del olvido. La correspondencia entre Francisco García Calderón y José de la Riva Agüero (Parte I)", en www.librosperuanos.com [Consultado el 27/08/13].

2012/13 "Del Novecientos al Centenario. La influencia de José Ingenieros en dos generaciones en el Perú", en Políticas de la Memoria, n $^{\mathrm{o}} 13,2012 / 2013$, pp. 78-95.

FEY, Ingrid.

1996 First Tango in Paris: Latin Americans in First-of-the-Century France. Tesis de doctorado, University of California.

LACHASSE, Pierre.

2002 "Revues littéraires d'avant-garde", en Jacqueline Pluet-Despatin, Michel Leymarie y Jean-Yves Mollier (dirs.), La belle époque des revues. Paris: Éditions de l'IMEC.

LOUÉ, Thomas.

2002 "Un modèle matriciel: les revues de culture générale", en Jacqueline Pluet-Despatin, Michel Leymarie y Jean-Yves Mollier (dirs.), La belle époque des revues. Paris: Éditions de l'IMEC.

MAILHE, Alejandra.

2013 'El laberinto de la soledad' del genio o las paradojas de El hombre mediocre", Varia Historia, Belo Horizonte, vol. 29, n 49, pp.197216, jan/abr de 2013.

MARTIN, Marc.

2002 "La revue et son lectorat. L'exemple des Annales Politiques et Littéraires", en Jacqueline Pluet-Despatin, Michel Leymarie y Jean- 
Yves Mollier (dirs.), La belle époque des revues. Paris: Éditions de l'IMEC.

MERBILHAÁ, Margarita.

2010 "Descifrar el presente para imaginar el destino americano: en torno a los ensayos de Manuel Ugarte y Francisco García Calderón" en Alejandra Mailhe (comp.), Pensar al otro pensar la nación. Intelectuales y cultura popular en Argentina y América Latina. La Plata: Al margen, pp. 20-45.

MOLLIER, Jean-Yves.

2002 "La revue dans le système éditorial", en Jacqueline Pluet-Despatin, Michel Leymarie y Jean-Yves Mollier (dirs.), La belle époque des revues. Paris: Éditions de l'IMEC.

RAMA, Ángel y Marlene POLO.

1979 "Cronología", en Francisco García Calderón, Las democracias latinas de América. La creación de un continente. Caracas: Ayacucho.

SAMUROVIC'-PAVLOVIC', Liliana.

1969 Les lettres hispano-américaines au Mercure de France (18971915). Paris: Centre de Recherches hispaniques, IEH.

SEGNINI, Yolanda.

2000 La Editorial-América de Rufino Blanco-Fombona. Madrid, 19151933. Madrid: Libris.

RAMOS, Julio.

1989 Desencuentros de la modernidad en América Latina. México: Fondo de Cultura Económica.

SuX, Alejandro.

1911 "Manuel Ugarte", Ideas y Figuras, a. 3, n 43, 11 de febrero.

UGARTE, Manuel.

1999 Epistolario (1896-1951). Buenos Aires: Archivo General de la Nación.

WILLIAMS, Raymond.

1977 Marxismo y literatura. Madrid: Península. 